\title{
A Cost-Utility Analysis of Trabecular Bypass Devices Versus Usual Care for Patients With Open-Angle Glaucoma
}

\author{
Paul R. Healey ${ }^{1} \cdot$ Dominic Tilden $^{2}\left(D \cdot\right.$ Dan Jackson $^{2} \cdot$ Lara Aghajanian $^{2}$
}

Accepted: 8 November 2021 / Published online: 10 December 2021

(c) The Author(s) 2021

\begin{abstract}
Objective The aim of this study was to determine whether insertion of a trabecular bypass device (TBD) is a cost-effective intervention for the treatment of open-angle glaucoma (OAG) with mild to moderate vision loss in the Australian setting.

Methods We performed a cost-utility analysis of TBD implantation in conjunction with cataract surgery or as a standalone procedure in patients with OAG. The model used a Monte Carlo simulation to follow individual patients through a glaucoma treatment algorithm that included TBD and compared the costs and outcomes with those of patients simulated through an algorithm without TBD (usual care). The model tracked the intraocular pressure (IOP) of individual patients and then, based on this IOP, tracked the progression of the patient's glaucoma. Utility values were assigned dependent on severity of glaucoma. The analysis took the perspective of the Australian health care system. The main outcome was incremental cost per quality-adjusted life-year (QALY) of TBD versus usual care for the treatment of OAG.

Results In the cataract surgery population, TBD surgery was associated with incremental healthcare costs of A $\$ 177$ and 0.0726 QALYs per patient, resulting in an incremental cost per QALY gained of A $\$ 2430$. In the standalone population, the overall incremental cost of TBD surgery versus usual care was A $\$ 2234$. With QALYs gained of 0.1526 per patient, this equated to an incremental cost per QALY gained ratio of A\$14,644.

Conclusion The incremental cost per QALY estimates for TBD were below thresholds generally accepted by Australian healthcare payers, suggesting that TBD is a cost-effective intervention for patients with primary OAG in the Australian setting.
\end{abstract}

\section{Key Points for Decision Makers}

The cost effectiveness of trabecular bypass devices (TBD) for glaucoma surgery in the Australian setting has not previously been established.

The incremental cost per quality-adjusted life-year gained of TBD in conjunction with cataract surgery or as a standalone procedure compared with usual care was estimated to be $\mathrm{A} \$ 2430$ and $\mathrm{A} \$ 14,644$, respectively.

The results of the cost-utility analysis suggest TBD surgery is a cost-effective intervention in addition to usual care in patients with open-angle glaucoma in the Australian setting.

Dominic Tilden

dtilden@thema.net

1 Centre for Vision Research Westmead Institute for Medical Research \& Save Sight Institute, University of Sydney, Sydney, NSW, Australia

2 THEMA Consulting Pty Ltd, Sydney, NSW, Australia

\section{Introduction}

Glaucoma is a chronic, irreversible, and incurable optic neuropathy characterised by progressive visual loss due to the death of retinal ganglion cells at the optic nerve head [1, 2]. It is the most common cause of irreversible blindness worldwide [2]. In Australia, glaucoma affects approximately $3 \%$ of the population over 50 years of age, rising to $8 \%$ of the population aged over 80 years [3]. Intraocular pressure (IOP) is the strongest risk factor for glaucoma [3]. Reduction of intraocular pressure reduces the rate and frequency of disease progression [4].

The primary goal of therapy for glaucoma is to lower IOP, which reduces the risk of vision loss [5, 6]. IOP can be reduced using pharmacotherapy, laser therapy or surgery. The choice of treatment is tailored to the patient's specific disease state, target IOP, and medical comorbidities. For the majority of patients, topical hypotensive medications are used first line. However, these may lead to eye redness, burning, itching, blurred vision, or changes in eye and/or eyelid skin colour, which may hamper adherence to therapy. Longterm use is associated with ocular surface disease, which 
leads to a reduction in the patient's quality of life (QoL) [7]. Poor persistence with therapy is common [8] and leads to both elevation and fluctuation in IOP, which has been shown to be associated with progressive visual field loss [4, 9]. In Australia, more than $50 \%$ of patients newly prescribed topical hypotensive therapy will discontinue treatment within 12 months [10].

For patients who are not adherent to topical hypotensives, or where these agents are ineffective at maintaining target IOP, alternative treatment options may be considered. One such option is laser trabeculoplasty, in which a laser is used to initiate cellular and biochemical changes in the trabecular meshwork to increase aqueous outflow [11].

Patients failing laser trabeculoplasty and medical therapy have limited treatment options. Traditional intraocular surgery to the trabecular meshwork, while highly effective in some childhood glaucomas, is generally considered ineffective in adults. Adults failing conservative therapies are usually subjected to a glaucoma filtering surgery such as trabeculectomy, which is usually substantially more symptomatic. Trabecular bypass devices (TBDs) describe a variety of minimally invasive intraocular stents, which when implanted through the trabecular meshwork, aim to reduce trabecular resistance, lowering IOP. TBD implantation may reduce the need for topical medication, and delay or avoid more invasive surgical interventions.

In Australia, new health care interventions, drugs and devices such as TBDs require an assessment of cost effectiveness before they will be subsidised through the health care system. The purpose of this study was to estimate the cost effectiveness of TBD surgery in patients with openangle glaucoma (OAG) in the Australian health care setting. The economic model described here formed the basis of an application for reimbursement to Australia's Medical Services Advisory Committee (MSAC).

\section{Methods}

\subsection{Population and Setting}

Two populations of patients likely to seek TBD surgery in Australia were included in the economic model: (i) patients with OAG and a cataract comorbidity requiring surgical intervention; and (ii) OAG patients who failed conservative therapies (i.e. ocular hypotensive medication, laser trabeculoplasty). The first group of patients would undergo TBD implantation in conjunction with cataract surgery, whilst the second group would undergo standalone TBD implantation. The demographic and clinical characteristics of patients as they enter the economic model are summarised in Table 1.

\subsection{Comparators}

The economic model followed individual patients through a typical glaucoma treatment algorithm of medications, followed by laser trabeculoplasty, followed by trabeculectomy (Fig. 1). The economic model compared an algorithm where patients do have access to TBDs with one in which they do not.

For patients undergoing TBD surgery in conjunction with cataract surgery, the comparator was cataract surgery alone with continued medical management of IOP by topical hypotensive drugs. For patients undergoing TBD surgery as a standalone procedure, the comparator was continued medical management. The choice of comparator reflects the positioning of TBD surgery in mild-to-moderate OAG patients as an alternative treatment where other conservative glaucoma management (i.e. topical medication and/or laser trabeculoplasty) has failed yet glaucoma severity is not yet at a stage that would warrant an invasive surgical intervention such as trabeculectomy.
Table 1 Baseline characteristics of the population in the economic model

\begin{tabular}{lll}
\hline Characteristic & Cataract surgery population [13] & Standalone population [12, 13] \\
\hline Age, years; mean (SD), [range] & $73(8)[48,98]$ & $64.4(10.0)[26,83]$ \\
Female, \% & 59.2 & 55.7 \\
IOP, mmHg; mean (SD) [range] & $18.4(3.2)[9.5,24.0]$ & $20.9(1.7)[9.5,24.0]$ \\
Visual field mean deviation, dB; & $-3.75(3.03) ;[-12,0]$ & $-3.75(3.03)[-12,0]$ \\
$\quad$ mean (SD) [range] & & \\
Number of prior medications; \% & & 0 \\
1 & 61 & 100 \\
2 & 24 & 0 \\
3 & 15 & \\
\hline
\end{tabular}

$d B$ decibels, $I O P$ intraocular pressure, $S D$ standard deviation

${ }^{a}$ Visual field mean deviation was not reported in (Fea) and hence sourced from (Samuelson) 


\subsection{Model Structure and Assumptions}

In parallel to the process of moving patients through the treatment algorithm, the model tracked the IOP of the individual patients, and then, based on this IOP, tracked the progression of the patient's glaucoma. It has been reported in multiple studies, including the Ocular Hypertension Treatment Study [15], the Early Manifest Glaucoma Trial [4, 16], the Beaver Dam Eye study [17] and the European Glaucoma Society's Terminology and Guidelines for Glaucoma [18], that the risk of optic nerve deterioration in a population of patients with OAG decreases by $10 \%$ for each 1-mmHg reduction in IOP. Progression rates and the effect of IOP lowering on slowing progression used in the model were based on published data from the Early Manifest Glaucoma Trial $[4,16]$. In the model, a patient with an IOP of $20.6 \mathrm{mmHg}$ has a rate of progression of 0.60 decibels $(\mathrm{dB})$ per annum. Relative to this, every 1 -mmHg decrease (or increase) in IOP will decrease (or increase) the rate of glaucoma progression by $9.5 \%$. For example, a patient in the model with an IOP of $21.6 \mathrm{mmHg}$ will experience a rate of progression of $0.657 \mathrm{~dB}[0.60 \times$ 1.095] per annum.

The core health states of the model were based on the Humphrey Field Analyzer mean deviation and defined by the Hodapp-Parrish-Anderson (HPA) glaucoma grading scale. These states were early defect (HPA $\geq-6 \mathrm{~dB})$; moderate defect (HPA $\geq-12$ to $<-6 \mathrm{~dB}$ ); advanced defect (HPA $\geq-20$ to $<-12 \mathrm{~dB}$ ); severe defect (HPA $\geq-30$ to $<-20 \mathrm{~dB}$ ); or end-stage disease (HPA $<$ $-30 \mathrm{~dB})$, Fig. 2.

\subsection{Measurement of Effectiveness}

A systematic review of published literature was performed in May 2017 in EMBASE, MEDLINE, clinical trial registries and hand-searching of reference lists and the Glaukos company database. Included studies were randomised controlled trials (RCTs) of patients with confirmed OAG that compared TBD implantation (iStent ${ }^{\circledR}$ and iStent inject ${ }^{\circledR}$ devices [Glaukos Corporation, Laguna Hills, CA, USA])

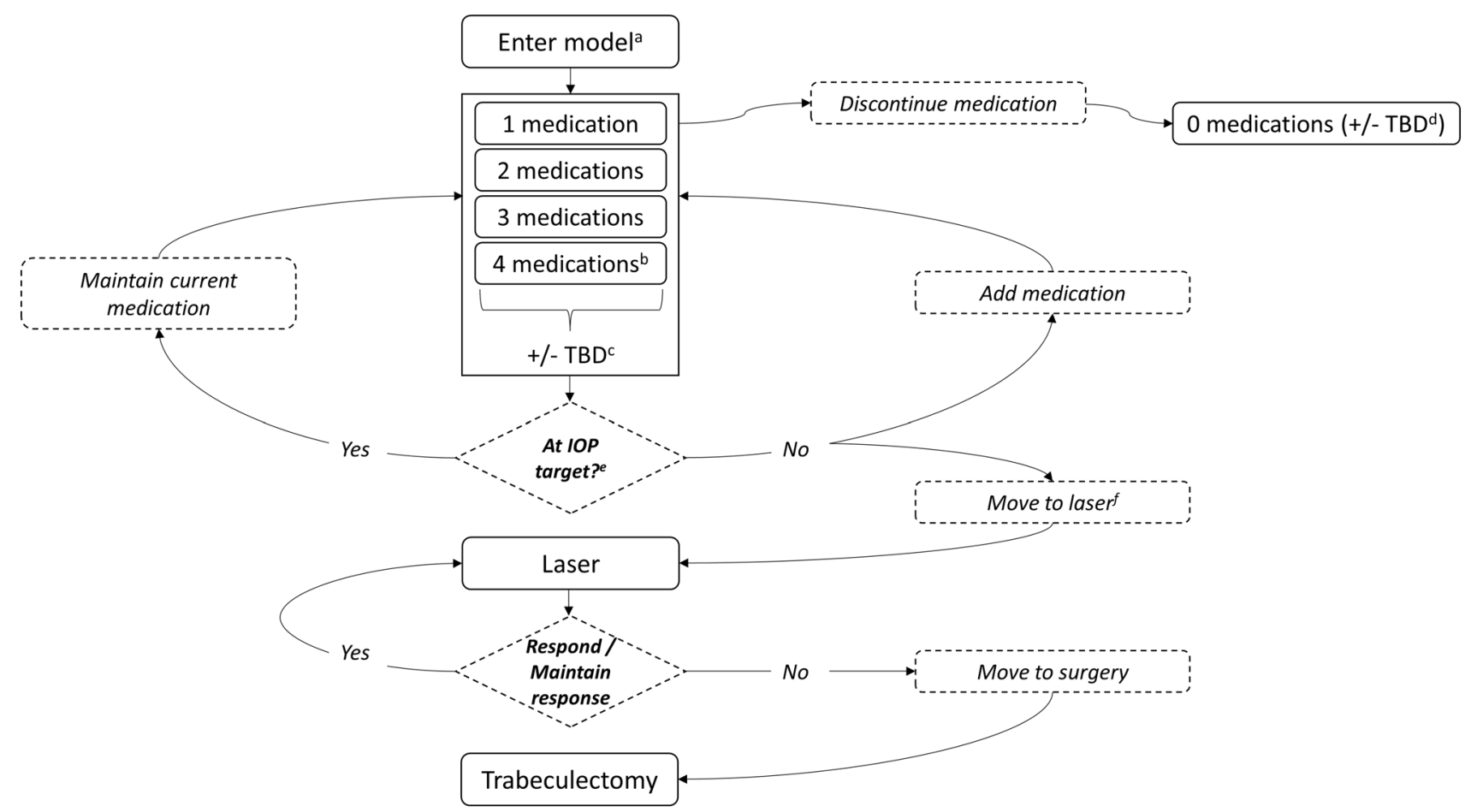

Fig. 1 Glaucoma treatment algorithms depicted in the model. IOP intraocular pressure, TBD trabecular bypass device. ${ }^{\text {a}}$ Patients enter the model on either 1, 2 or 3 glaucoma medications. The impact of TBD surgery will influence the number of medications and this is

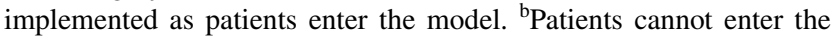
model on 4 medications, but may end up on 4 medications as medications are added due to IOP not meeting target. ${ }^{\mathrm{c}}$ The structure and nature of the usual care treatment algorithm does not change in the TBD arm of the model. However, the rate at which patients reach IOP target and progress through the algorithm is affected. ${ }^{\mathrm{d}}$ Patients who discontinue medication in the TBD arm of the model will still receive IOP efficacy of the TBD because it is not possible to discontinue TBD. ${ }^{\text {e}}$ The patient's IOP is assessed against target every 12 months in the model. ${ }^{\mathrm{f}}$ Whether a patient not at target will add a medication or move to laser is based on Australian data indicating the number of anti-glaucoma medications a cohort of laser patients were on at the time of the laser intervention [14] 
used in combination with cataract surgery or TBD surgery as a standalone procedure. Studies were selected by a single reviewer. An assessment of bias of each study, and across studies was assessed using the GRADE criteria [19]. Studies were combined meta-analytically using random effects models (see electronic supplementary material [ESM]).

As patients progress through the algorithm, the model assigned an effectiveness, measured in terms of change in IOP, to each intervention received. These values are summarised in Table 2.

\subsection{Quality of Life Measurement}

Utility values were assigned to each of the five glaucoma severity health states based on published values [20, 21]. These utility values were early defect 0.80 ; moderate defect 0.75 , advanced defect 0.71 , severe defect 0.54 , and end stage 0.26 . Utility values were identified from the literature during the development phase of the economic model and were deemed the most appropriate for the model structure. Utility values were tested via sensitivity analysis.

\subsection{Estimating Resources and Costs}

All costs included in the model were denominated in Australian dollars (2017 values) and reflected the Australian health care payer perspective. Costs included the TBD intervention and associated surgery (Table 3), medication costs, other procedure costs, and health state costs, which account for differences in resource use by disease severity (Table 2). At the time of writing, standalone TBD devices were not

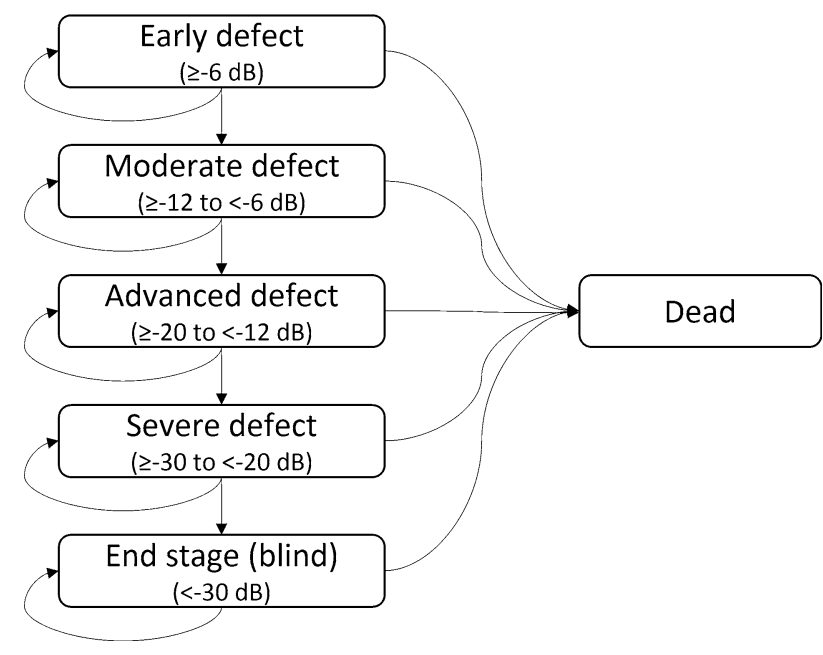

Fig. 2 Possible transitions through the health states in the model. $d B$ decibels reimbursed in Australia. Therefore, the cost of the procedure was based on the reimbursed fee for a goniotomy procedure.

The cost and QoL impact of adverse events were not explicitly included in the model for any of the interventions throughout the algorithm. For TBD, these events occur rarely $(<1 \%)$ and are generally resolved within the time period of the hospitalisation for the TBD surgery, the cost of which is included in the model. To the extent TBD is able to delay or avoid trabeculectomy, this assumption is likely to be biased against TBD. The effect of adverse events with topical hypotensives is captured in the economic model by the role they play in causing patients to discontinue treatment and the consequent impact this has on treatment efficacy and health outcomes. Sensitivity analysis tested the impact of including the cost of adverse events on the model results.

\subsection{Model Time Horizon}

Given glaucoma is an incurable, progressive condition, patients will live with the condition for the remainder of their lives. It may take a substantial amount of time for patients to cycle through all available glaucoma treatments, and as such, a short time horizon is likely to underestimate the costs and effects of TBD surgery towards the end of the treatment algorithm. However, in order to avoid uncertain extrapolations over an extended period, the model was conservatively limited to a duration of 15 years. Age- and sex-specific all-cause mortality was applied to patients in each cycle of the model. Mortality rates were sourced from Australian life tables. Patients in the end-stage health state (blindness) had an age- and sex-controlled mortality risk $54 \%$ higher than the general population [22]. All costs and outcomes are discounted at a rate of 5\%, as recommended by the MSAC [23].

\subsection{Analytic Methods}

The model simulated 500,000 individual patients through a Monte Carlo simulation which aggregated the costs and quality-adjusted life-years (QALYs) accrued by patients as they transited through the model. IOP was assessed at annual intervals in the model, at which time further medication could be added if available, or laser therapy commenced. The glaucoma treatment algorithms presented in Fig. 1 also represent a flowchart of the simulation process. Incremental cost-effectiveness ratios were calculated from the mean costs and QALYs of each arm of the model across these simulations. Inputs into the model included population characteristics, clinical effectiveness, RCT evidence, treatment algorithm variables, natural history of glaucoma, utility inputs, cost inputs, mortality and death rates, time horizon and discounting (Tables 2 and 3). The cost-utility 
Table 2 Model input variables

\begin{tabular}{|c|c|c|c|}
\hline Model input & TBD & Usual care & Source \\
\hline \multicolumn{4}{|l|}{ Effectiveness variables } \\
\hline $\begin{array}{l}\text { Change in IOP from baseline to end- } \\
\text { point, mean (SD) }\end{array}$ & $\begin{array}{l}\text { CS pop: }-1.69(3.0) \\
\text { SA pop: }-8.1(2.6)\end{array}$ & $\begin{array}{l}\text { CS pop: }-1.08(3.0) \\
\text { SA pop: }-7.3(2.2)\end{array}$ & $\begin{array}{l}\text { CS: pooled result }[13,22] \\
\text { SA: [12] }\end{array}$ \\
\hline $\begin{array}{l}\text { Change in number of ocular medica- } \\
\text { tions from baseline to endpoint, } \\
\text { mean }\end{array}$ & $\begin{array}{l}\text { CS pop: }-0.45 \\
\text { SA pop: }-1^{\mathrm{a}}\end{array}$ & $\mathrm{n} / \mathrm{a}$ & 12 months: pooled result $[13,23,24]$ \\
\hline \multicolumn{4}{|l|}{$\begin{array}{l}\text { Effectiveness of downstream interven- } \\
\text { tions }\end{array}$} \\
\hline $\begin{array}{l}\text { Change in IOP with each added medi- } \\
\text { cation, mean (SD) }\end{array}$ & \multicolumn{2}{|l|}{$-2.33(0.66)$} & [23] \\
\hline $\begin{array}{l}\text { Probability of patient responding to } \\
\text { SLT }\end{array}$ & \multicolumn{2}{|l|}{0.80} & [11] \\
\hline $\begin{array}{l}\text { Probability of SLT response at } \\
60 \text { months }\end{array}$ & \multicolumn{2}{|l|}{0.187} & [14] \\
\hline \multirow{4}{*}{$\begin{array}{l}\text { Long-term changes in IOP changes } \\
\text { per annum, } \mathrm{mmHg}\end{array}$} & Medication and TBD & 0.4000 & [23] \\
\hline & TBD only & 0.4667 & \\
\hline & Medicated only & 0.4667 & \\
\hline & Discontinued & 0.6667 & \\
\hline $\begin{array}{l}\text { Change in IOP upon medication } \\
\text { discontinuation, } \mathrm{mmHg}\end{array}$ & 7 & & [13] \\
\hline \multicolumn{4}{|l|}{ Treatment algorithm variables } \\
\hline Treatment response threshold & \multicolumn{2}{|l|}{$20 \%$} & [27] \\
\hline Medication assessment frequency & \multicolumn{2}{|l|}{ Annual } & Clinical expert opinion \\
\hline Medications tried before SLT & & & [14] \\
\hline If 1 medication at baseline & \multicolumn{2}{|l|}{ 1: $29.1 \%, 2: 53.8 \%, 3: 8.55 \%, 4: 8.55 \%$} & \\
\hline If $>1$ medication at baseline & \multicolumn{2}{|l|}{$3: 50 \%, 4: 50 \%$} & \\
\hline $\begin{array}{l}\text { Responses to SLT before trabeculec- } \\
\text { tomy }\end{array}$ & \multicolumn{2}{|l|}{3} & Clinical expert opinion \\
\hline \multicolumn{4}{|l|}{ Persistence to medication } \\
\hline $12,24,36$ months & \multicolumn{2}{|l|}{$8 \%, 29 \%, 25 \%$} & [8] \\
\hline \multicolumn{4}{|l|}{ Natural history of glaucoma } \\
\hline Progression rate (dB, per annum) & \multicolumn{2}{|l|}{0.6 for patient with IOP of $20.6 \mathrm{mmHg}$} & {$[4,15]$} \\
\hline Change in rate of progression & \multicolumn{2}{|l|}{$-9.5 \%$ for every $1-\mathrm{mmHg}$ reduction in IOP } & \\
\hline \multicolumn{4}{|l|}{ Utility values } \\
\hline Early & \multicolumn{2}{|l|}{0.80} & [17] \\
\hline Moderate & \multicolumn{2}{|l|}{0.75} & \\
\hline Advanced & \multicolumn{2}{|l|}{0.71} & \\
\hline Severe & \multicolumn{2}{|l|}{0.54} & \\
\hline End stage & \multicolumn{2}{|l|}{0.26} & [18] \\
\hline \multicolumn{4}{|l|}{ Cost inputs } \\
\hline Glaucoma medication per month & \multicolumn{2}{|l|}{$\$ 19.11$} & Weighted average of PBS medications \\
\hline $\mathrm{TBD}+\mathrm{CS}$ & \multicolumn{2}{|l|}{$\$ 4438.21$} & See Table 3 \\
\hline CS alone & $\$ 2562.88$ & & See Table 3 \\
\hline TBD standalone & $\$ 3401.50$ & & See Table 3 \\
\hline SLT & $\$ 603.15$ & & MBS items 42782, 17610, 20140 \\
\hline Trabeculectomy & $\$ 4383.02$ & & $\begin{array}{l}\text { DRG C16Z. National Hospital Cost } \\
\text { Data Collection, AR-DRG Cost } \\
\text { Weight tables V8.0x, Round } 21 \\
\text { (2016-17 financial year) }\end{array}$ \\
\hline Health state costs per annum & & & \\
\hline
\end{tabular}


Table 2 (continued)

\begin{tabular}{|c|c|c|}
\hline Model input & Usual care & Source \\
\hline Early & $\begin{array}{l}\$ 229.44 \text { (3 office visits, } \mathrm{A} \$ 44.35+1.4 \text { visual field tests, } \\
\$ 68.85 \text { ) }\end{array}$ & \multirow{6}{*}{$\begin{array}{l}\text { Resource use: [28] } \\
\text { Unit costs: MBS items } 105 \text { and } 11221 \text {, } \\
\text { respectively }\end{array}$} \\
\hline Moderate & $\$ 240.76$ (3.1 and 1.5) & \\
\hline Advanced & $\$ 267.84(3.4$ and 1.7$)$ & \\
\hline Severe & $\$ 274.26$ (3.7 and 1.6) & \\
\hline End stage & $\$ 232.95$ (3.7 and 1.0) & \\
\hline \multicolumn{2}{|l|}{ Mortality } & \\
\hline Probability of death & Various, by age and sex & $\begin{array}{l}\text { ABS: 3302.0.55.001-Life Tables, } \\
\text { 2015-2017 }\end{array}$ \\
\hline $\begin{array}{l}\text { Standardised mortality ratio in end- } \\
\text { stage (blind) health state }\end{array}$ & 1.54 & [19] \\
\hline \multicolumn{3}{|l|}{ Other variables } \\
\hline Model time horizon & 15 years & Assumption \\
\hline Annual discount rate & $5 \%$ & [20] \\
\hline
\end{tabular}

Costs are in Australian dollars and current as of July 2017

$A B S$ Australian Bureau of Statistics, $A R-D R G$ Australian Refined Diagnosis Related Groups, $C S$ cataract surgery, $d B$ decibels, $I O P$ intraocular pressure, MBS Medicare Benefits Schedule, PBS Pharmaceutical Benefits Scheme, pop population, SA standalone, SD standard deviation, SLT selective laser trabeculoplasty, $T B D$ trabecular bypass device

${ }^{a}$ In the SA population, the change in medication was dictated by the trial protocols. The model compares TBD surgery with a reduction of one medication to usual care arm with no change in number of medications

Table 3 Costs of TBD and cataract surgery procedures applied in the economic model

\begin{tabular}{|c|c|c|c|c|}
\hline Procedure & $\mathrm{TBD}+\mathrm{CS}$ & CS alone & TBD SA & Source \\
\hline \multicolumn{5}{|l|}{ Hospital admission } \\
\hline Private day hospital expenditure for ophthalmic surgery & $\$ 1026.00$ & $\$ 1026.00$ & $\$ 1026.00$ & ABS $2014^{\mathrm{a}}$ \\
\hline \multicolumn{5}{|l|}{ Professional services } \\
\hline $\begin{array}{l}\text { Lens extraction and insertion of intraocular lens with trabecular } \\
\text { bypass stent implant (if applicable) }\end{array}$ & $\$ 925.70$ & $\$ 772.80$ & & $\begin{array}{l}\text { MBS items } 42705 \text { and } \\
42702 \text { respectively }\end{array}$ \\
\hline Glaucoma surgery component-TBD stent implant & & & $\$ 710.65$ & MBS item 42758 (as proxy) \\
\hline Pre-anaesthesia consultation & $\$ 44.35$ & $\$ 44.35$ & $\$ 44.35$ & MBS item 17610 \\
\hline Initiation and management of anaesthesia—lens surgery & $\$ 120.60$ & $\$ 120.60$ & & MBS item 20142 \\
\hline Initiation and management of anaesthesia-other eye procedure & & & $\$ 100.50$ & MBS item 20140 \\
\hline \multicolumn{5}{|l|}{ Prostheses } \\
\hline Posterior intraocular lens & $\$ 599.13$ & $\$ 599.13$ & & Prostheses List ${ }^{\mathrm{b}}$ \\
\hline TBD & $\$ 1520.00$ & & $\$ 1520.00$ & Prostheses List (RQ075) \\
\hline Total cost of procedure applied in the model & $\$ 4235.78$ & $\$ 2562.88$ & $\$ 3401.50$ & \\
\hline
\end{tabular}

Costs are in Australian dollars and current as of July 2017

ABS Australian Bureau of Statistics, $C S$ cataract surgery, MBS Medicare Benefits Schedule, $S A$ standalone, $T B D$ trabecular bypass device ${ }^{a}$ ABS 4390.0 Private Hospitals (2013-14). Day Hospital Expenditure, average expenditure per separation, ophthalmic surgery

${ }^{\mathrm{b}}$ Average benefit for all posterior intraocular lens (01.02)

analysis calculated the incremental cost per QALY gained of adding TBD to the usual care algorithm.

The review of the literature from databases or handsearching identified 79 records. Studies were included if they included a randomisation procedure in their design, were a comparative trial of TBD implantation using the iStent ${ }^{\circledR}$ or iStent inject ${ }^{\circledR}$ devices used in combination with cataract surgery or as a standalone procedure and included patients 
with confirmed OAG. Overall, three RCTs of patients undergoing TBD implantation with an iStent ${ }^{\circledR}$ or iStent inject ${ }^{\circledR}$ device in conjunction with cataract surgery [13, 24-27] and three RCTs in patients undergoing TBD implantation with an iStent ${ }^{\circledR}$ or iStent inject ${ }^{\circledR}$ device as a standalone procedure $[12,28,29]$ were identified. The randomised studies of TBD surgery in conjunction with cataract surgery and TBD surgery as a standalone procedure were assessed as being of moderate quality according to GRADE criteria [19].

The effect of TBD surgery on patient outcomes was modelled on the basis of a reduction in IOP and a reduction in medication use. However, these were not independent of each other. Whilst the model avoided any potential for double counting by using internally consistent values from RCTs, the results may be subject to the way patients were treated in the trials, and therefore the trial protocols may impact the estimates. Other trials of TBD surgery have used medications differently with TBD surgery, resulting in a different trade-off between IOP change and medication change [12]. IOP change and medication change were tested in sensitivity analysis. Other sensitivity analyses were also performed using various changes in baseline clinical characteristics including age, baseline IOP, glaucoma severity at baseline, and baseline number of medications. The model was constructed and analysed using TreeAge software. Due to the computational burden of the individual patient simulation, probabilistic sensitivity analyses were unable to be undertaken. In lieu of this, an extensive range of univariate sensitivity analysis was undertaken to understand key structural and parameter uncertainty. Categories of parameters tested included population characteristics, treatment efficacy, downstream effectiveness, unit costs, adverse event costs, utility values and model structural variables such as time horizon and discounting, with the uncertainty of parameter values tested within plausible ranges.

\section{Results}

\subsection{Base-Case Results}

In the cataract surgery population, treatment with TBD delayed utilisation of laser trabeculoplasty and trabeculectomy compared with usual care. Over the model duration, TBD surgery was associated with incremental healthcare costs of $A \$ 177$ per patient. The additional cost of TBD surgery (A $\$ 1673$ per patient) was partially offset by, in decreasing order of magnitude, lower trabeculectomy costs (A $\$ 692$ per patient), lower medication costs (A $\$ 417$ per patient) and lower laser trabeculoplasty costs (A $\$ 383$ per patient). TBD surgery resulted in a gain of 0.0726 QALYs per patient over the course of the model (Table 4). The incremental cost per QALY gained ratio was $\mathrm{A} \$ 2430$.

In the standalone population, the overall incremental cost of TBD surgery from the healthcare perspective versus usual care was $\mathrm{A} \$ 2234$. With QALYs gained of 0.1526 per patient, this equated to an incremental cost per QALY gained ratio of $\mathrm{A} \$ 14,644$ (Table 4).

\subsection{Characterising Uncertainty}

In sensitivity analyses, the most important variables of the model were the effect of TBD surgery on IOP and medication reduction. The model was more sensitive to medication change than IOP change relative to usual care. The time horizon was an important determinant of the cost effectiveness, given the QALYs gained from avoiding or delaying events with permanent consequences (blindness or death for example). The model results were robust to most other variables tested with the ICER not increasing beyond A $\$ 50,000$ per QALY in any plausible scenario tested (see Fig. 3 and the ESM). When included, adverse events had little impact on the incremental cost per QALY results due to their relatively rare occurrence and generally short-term effects.

\subsection{Characterising Heterogeneity}

The incremental cost per QALY gained is higher in the standalone setting compared with the concurrent cataract surgery setting due to the increased incremental cost of the TBD procedure. Overall, TBD surgery remained cost effective compared with usual care.

\section{Discussion}

Results of this economic evaluation suggest that use of TBD stents compared with usual care in patients with primary OAG is cost effective, with an ICER of A $\$ 2430$ in the cataract surgery setting and an incremental cost per QALY gained of A $\$ 14,644$ in the standalone setting. Similar or more favourable findings were identified in recently published literature in European and Canadian health care settings for mild to moderate $\mathrm{OAG}$ in both the cataract surgery [33-35] and standalone populations [36].

As with any economic model, our analysis has limitations, governed by data availability and our assumptions. For example, the clinical data that informed this analysis was taken from a relatively small number of clinical trials, which may impact the estimates used within the model. Second, the economic model is complex in that it tracks individual patients through a glaucoma treatment algorithm of 
Table 4 Results of the economic model

\begin{tabular}{|c|c|c|c|}
\hline Model output & $\mathrm{TBD}+\mathrm{CS}$ & $\mathrm{CS}$ & Incremental cost \\
\hline \multicolumn{4}{|c|}{$\begin{array}{l}\text { Results of the economic evaluation of TBD + cataract surgery } \\
\text { versus cataract surgery alone }\end{array}$} \\
\hline TBD and/or cataract surgery & $\$ 4236$ & $\$ 2563$ & $\$ 1673$ \\
\hline Medications costs & $\$ 1141$ & $\$ 1558$ & $-\$ 417$ \\
\hline SLT costs & $\$ 195$ & $\$ 578$ & $-\$ 383$ \\
\hline Filtering surgery & $\$ 341$ & $\$ 1033$ & $-\$ 692$ \\
\hline Health state costs & $\$ 2033$ & $\$ 2037$ & $-\$ 4$ \\
\hline Total costs & $\$ 7946$ & $\$ 7770$ & $\$ 177$ \\
\hline Total QALYs & 6.5095 & 6.4369 & 0.0726 \\
\hline Incremental cost effectiveness & & & $\$ 2430$ \\
\hline Model output & TBD & Usual care & Incremental cost \\
\hline \multicolumn{4}{|c|}{$\begin{array}{l}\text { Results of the economic evaluation of TBD standalone versus } \\
\text { usual care }\end{array}$} \\
\hline TBD & $\$ 3402$ & $\$ 0$ & $\$ 3402$ \\
\hline Medication & $\$ 905$ & $\$ 1841$ & $-\$ 936$ \\
\hline SLT & $\$ 3$ & $\$ 81$ & $-\$ 78$ \\
\hline Trabeculectomy & $\$ 4$ & $\$ 135$ & $-\$ 131$ \\
\hline Health state & $\$ 2280$ & $\$ 2302$ & $-\$ 22$ \\
\hline Total costs & $\$ 6594$ & $\$ 4360$ & $\$ 2234$ \\
\hline QALYs & 7.3390 & 7.1864 & 0.1526 \\
\hline ICER & & & $\$ 14,644$ \\
\hline
\end{tabular}

Costs are in Australian dollars. Total costs and QALYs are subject to rounding

$C S$ cataract surgery, ICER incremental cost-effectiveness ratio, $Q A L Y$ quality-adjusted life-year, $S L T$ selective laser trabeculoplasty, $T B D$ trabecular bypass device

medications, laser trabeculoplasty and trabeculectomy whilst simultaneously tracking the natural history of glaucoma and its impact on the patient's QoL. For this reason, several sensitivity analyses were conducted to assess the impact of our assumptions on the model. Finally, the conventional algorithm for conservative glaucoma practice in Australia will not necessarily represent the clinical reality for all patients. Patients may be intolerant to, or contraindicated to topical hypotensive medication, may be unsuitable candidates for laser therapy, and therefore may not progress through the management algorithm in a linear manner. Consequently, the patient population who will access TBD in clinical practice may be heterogeneous in terms of treatment history.

Our model has limitations to be considered when assessing its applicability to clinical practice and to reimbursement decision making. Firstly, as the perspective was of a third-party payer, and not of a societal one, indirect costs and out-of-pocket direct costs incurred by the patient were not included. Second, the costs of adverse events were also omitted. Nevertheless, the model incorporated a number of assumptions that underestimate the value of adding TBD surgery to the glaucoma treatment algorithm. These include the omission of adverse event costs associated with glaucoma medications and downstream procedures (which is likely biased against TBD); the burden of glaucoma medication on a patient's QoL is not capture in the model; and the time horizon may underestimate longer-term benefits of TBD. As acknowledged earlier, some uncertainty exists for the cost of the TBD procedure in the analysis due to not being reimbursed in Australia at the time of publication; however, the cost of goniotomy serves as a useful proxy. Clinicians involved in the analysis considered goniotomy to be the procedure that is most similar to trabecular bypass minimally invasive glaucoma surgery (MIGS) stent implantation in terms of relative intensity and technical skill.

The health state utility values used in the analysis were ultimately reliant on personal communication [19] or were derived from low patient numbers [20] and is acknowledged here as a limitation of the analysis. However, it should be noted that the overall cost effectiveness of TBD was not greatly impacted by changes in utility differences between health states or the utility value for end-stage disease (blindness) as shown by the sensitivity analysis (see ESM), and hence did not change any of the overall conclusions from the analysis.

The incremental cost per QALY gained estimated in the economic model represents good value for money in 
(a)

Mean age at baseline $[\leq 69 />76]$

Model time horizon, years [20/10]

Discount rate $[0 \% / 10 \%]$

Costs of trabeculectomy $[+50 \% /-50 \%]$

Medication costs $[+50 \% /-50 \%]$

Annual rate of $\mathrm{dB}$ progression for patient with $20.6 \mathrm{IOP}[+50 \% /-50 \%]$

Mean change in medication use [-0.64/-0.24]

Costs of laser $[+50 \% /-50 \%]$

Mean IOP change [-2.47/-1.08]

AE costs per TBD procedure [A\$0/A\$200]

Treatment response threshold [10\%/30\%]

Baseline IOP $[>19.5 / \leq 17]$

Baseline number of medications $[3 / 1]$

Probability of treatment discontinuation [-50\%/ $+50 \%]$

Medication assessment interval, mo. [6/18]

Change in IOP over time $[+50 \% /-50 \%]$

IOP improvement when medication added [3/1]

Coefficient correlating IOP to rate of visual field loss [0.19]

Maximum laser procedures for laser responders [2/1]

Utility values by glaucoma severity health state [Diff $+50 \% / D i f f-50 \%]$

Responders to laser [90\%/70\%]

Glaucoma severity at baseline $[\operatorname{Mod}(\geq-12$ to $<-6) /$ Early $(\geq-6)]$

Utility values for blindness [0.1/0.4]

IOP change for responders to laser $[-2 /-6]$

Costs of glaucoma health states [ $+50 \% /-50 \%]$

Excess Mortality in blindness health state [1.54]

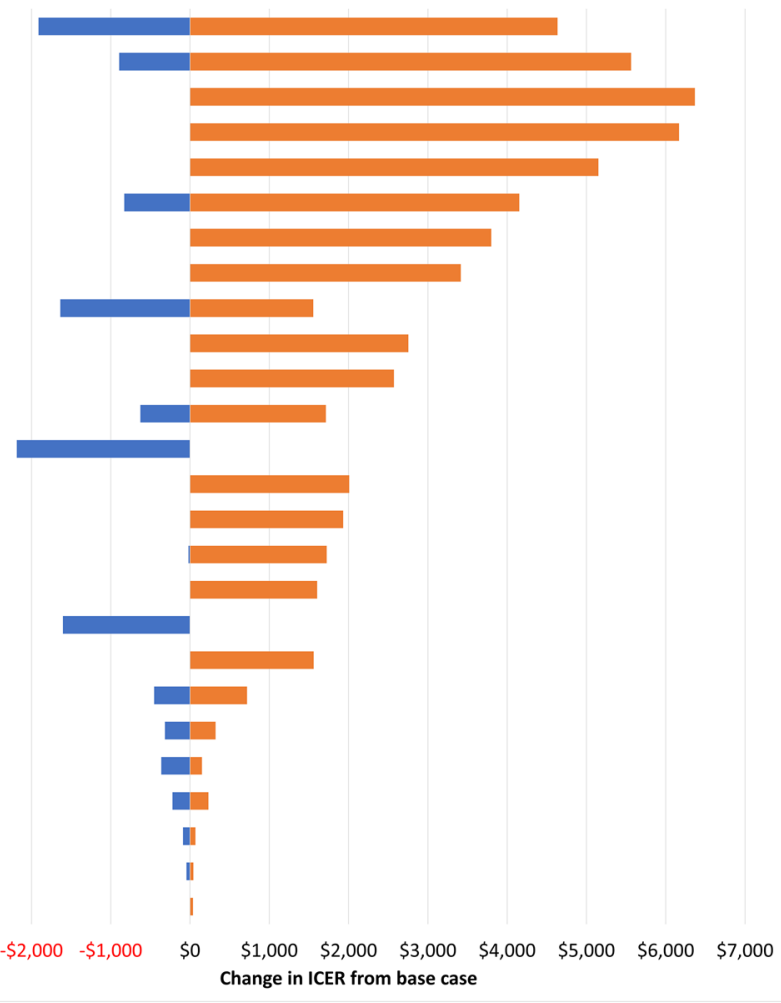

(b)

Model time horizon, years [20/10] Annual rate of $\mathrm{dB}$ progression for patient with 20.6 IOP [+50\%/-50\%] Mean change in medication use $[-2 / 0]$ Discount rate $[0 \% / 10 \%]$

Change in IOP over time [+50\%/-50\%] Utility values by glaucoma severity health state [Diff $+50 \% / D$ iff $-50 \%$ ] Coefficient correlating IOP to rate of visual field loss [0.19/9.53\%]

Medication costs [+50\%/-50\%]

IOP improvement when medication added [3/1]

Utility values for blindness [0.1/0.4]

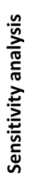

Glaucoma severity at baseline $[\operatorname{Mod}(\geq-12$ to $<-6) /$ Early $(\geq-6)]$

Treatment response threshold [30\%/10\%]

AE costs per TBD procedure [A\$0/A\$200]

Mean IOP change [-8.5/-7.7]

Costs of trabeculectomy $[+50 \% /-50 \%]$

Baseline number of medications $[1 / 3]$ Costs of laser $[+50 \% /-50 \%]$

Probability of treatment discontinuation $[-50 \% /+50 \%]$ Baseline IOP $[>19.5 / \leq 17]$

Excess Mortality in blindness health state [1.54]

Costs of glaucoma health states [ $+50 \% /-50 \%]$

Medication assessment interval, mo. [18/6]

Maximum laser procedures for laser responders [2/1]

Mean age at baseline $[>76 / \leq 69]$

IOP change for responders to laser $[-2 /-6]$ Responders to laser [90\%/70\%]

$\$ 15,000-\$ 10,000-\$ 5,000$

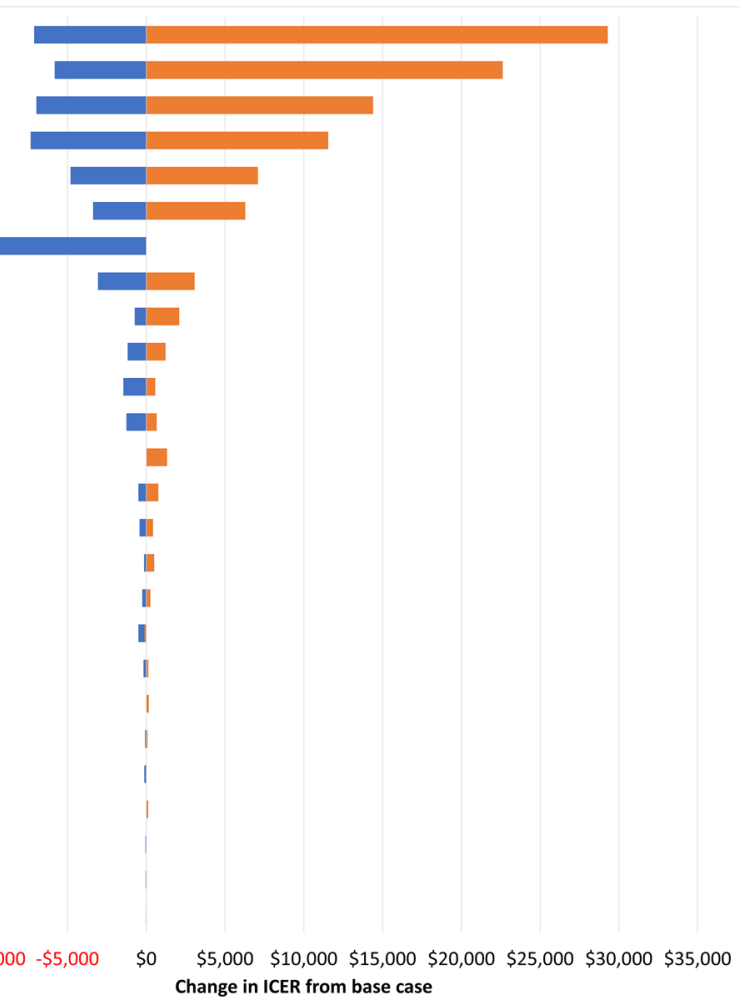

Fig. 3 Results of the sensitivity analyses in the $\mathbf{a}$ concurrent cataract surgery and $\mathbf{b}$ standalone settings presented as tornado diagrams 
both the cataract surgery and standalone populations. The results of our model are below incremental cost per QALY thresholds generally accepted by Australian health care payers [31, 32], suggesting that (notwithstanding the limitations described above) TBD surgery is a cost-effective intervention in addition to usual care in patients with OAG in the Australian setting.

Supplementary Information The online version contains supplementary material available at https://doi.org/10.1007/s41669-021-00312-4.

Acknowledgements The authors thank Belinda Butcher BSc (Hons) MBiostat PhD CMPP of WriteSource Medical Pty Ltd, Sydney, Australia, for providing medical writing support, which was funded by Glaukos Corporation, Laguna Hills, CA, in accordance with Good Publication Practice (GPP3) guidelines (http://www.ismpp.org/gpp3).

\section{Declarations}

Funding THEMA Consulting, owned by D.T., received consulting fees for this work from Glaukos Corporation, the manufacturer of iStent ${ }^{\circledR}$ and iStent inject ${ }^{\circledR}$, as part of a reimbursement submission to the Australian Medical Services Advisory Committee (MSAC). Glaukos had no editorial input in the writing of this manuscript.

Conflict of interest D.T. is the Director and D.J. and L.A. are employees of THEMA Consulting, a health economics consultancy that received consulting fees from Glaukos Corporation for this work as part of a reimbursement submission to MSAC. P.H. has no direct competing interest but has in the past received honoraria from both Glaukos and Ivantis, who manufacture TBDs, and from Allergan and Novartis, who manufacture glaucoma drops.

Ethics approval Not applicable.

Consent Not applicable.

Availability of data and material The data used in our analyses were taken from published or publicly available sources.

Code availability The model files are available from the corresponding author on reasonable request.

Author contributions All authors contributed to the study conception and design. D.T., D.J. and L.A. contributed to identification and sourcing of inputs and the development of the economic model. P.H. contributed clinical expert opinion and review and revisions to the model, inputs and manuscript. All authors contributed to drafting, reviewing and approving the final manuscript.

Open Access This article is licensed under a Creative Commons Attribution-NonCommercial 4.0 International License, which permits any non-commercial use, sharing, adaptation, distribution and reproduction in any medium or format, as long as you give appropriate credit to the original author(s) and the source, provide a link to the Creative Commons licence, and indicate if changes were made. The images or other third party material in this article are included in the article's Creative Commons licence, unless indicated otherwise in a credit line to the material. If material is not included in the article's Creative Commons licence and your intended use is not permitted by statutory regulation or exceeds the permitted use, you will need to obtain permission directly from the copyright holder. To view a copy of this licence, visit http://creativecommons.org/licenses/by-nc/4.0/.

\section{References}

1. Kwon YH, Fingert JH, Kuehn MH, et al. Primary open-angle glaucoma. N Engl J Med. 2009;360(11):1113-24.

2. Quigley HA, Broman AT. The number of people with glaucoma worldwide in 2010 and 2020. Br J Ophthalmol. 2006;90(3):262-7.

3. Mitchell P, Smith W, Attebo K, et al. Prevalence of open-angle glaucoma in Australia. The Blue Mountains Eye Study. Ophthalmology. 1996;103(10):1661-9.

4. Heijl A, Leske MC, Bengtsson B, et al. Reduction of intraocular pressure and glaucoma progression: results from the Early Manifest Glaucoma Trial. Arch Ophthalmol. 2002;120(10):1268-79.

5. Maier PC, Funk J, Schwarzer G, et al. Treatment of ocular hypertension and open angle glaucoma: meta-analysis of randomised controlled trials. BMJ. 2005;331(7509):134.

6. Hyman L, Heijl A, Leske MC, et al. Natural history of intraocular pressure in the early manifest glaucoma trial: A 6-year follow-up. Arch Ophthalmol. 2010;128(5):601-7.

7. Ramos-Cadena MDLA, Spaeth GL. Ocular surface disease and glaucoma. Expert Rev Ophthalmol. 2016;11(3):215-26.

8. Nordstrom BL, Friedman DS, Mozaffari E, et al. Persistence and adherence with topical glaucoma therapy. Am J Ophthalmol. 2005;140(4):598-606.

9. Caprioli J, Coleman AL. Intraocular pressure fluctuation a risk factor for visual field progression at low intraocular pressures in the advanced glaucoma intervention study. Ophthalmology. 2008;115(7):1123-1129.e1123.

10. Healey PR, Goldberg I, Subramaniam K, et al. Persistence and adherence to glaucoma therapy in Australia. World Glaucoma Congress. 2011;E-abstract P504.

11. Wong MO, Lee JW, Choy BN, et al. Systematic review and metaanalysis on the efficacy of selective laser trabeculoplasty in openangle glaucoma. Surv Ophthalmol. 2015;60(1):36-50.

12. Fea AM, Belda JI, Rekas M, et al. Prospective unmasked randomized evaluation of the iStent inject $((\mathrm{R}))$ versus two ocular hypotensive agents in patients with primary open-angle glaucoma. Clin Ophthalmol. 2014;8:875-82.

13. Samuelson TW, Katz LJ, Wells JM, et al. Randomized evaluation of the trabecular micro-bypass stent with phacoemulsification in patients with glaucoma and cataract. Ophthalmology. 2011;118(3):459-67.

14. Woo DM, Healey PR, Graham SL, et al. Intraocular pressurelowering medications and long-term outcomes of selective laser trabeculoplasty. Clin Exp Ophthalmol. 2015;43(4):320-7.

15. Kass MA, Heuer DK, Higginbotham EJ, et al. The ocular hypertension treatment study: a randomized trial determines that topical ocular hypotensive medication delays or prevents the onset of primary open-angle glaucoma. Arch Ophthalmol. 2002;120(6):701-13.

16. Leske MC, Heijl A, Hussein M, et al. Factors for glaucoma progression and the effect of treatment: the early manifest glaucoma trial. Arch Ophthalmol. 2003;121(1):48-56.

17. Klein BE, Klein R, Linton KL. Intraocular pressure in an American community. The Beaver Dam Eye Study. Invest Ophthalmol Vis Sci. 1992;33(7):2224-8. 
18. European Glaucoma Society Terminology and Guidelines for Glaucoma, 4th Edition-Part 1 Supported by the EGS Foundation. Br J Ophthalmol. 2017;101(4):1-72.

19. Guyatt G, Oxman AD, Akl EA, et al. GRADE guidelines: 1 . Introduction-GRADE evidence profiles and summary of findings tables. J Clin Epidemiol. 2011;64(4):383-94.

20. Crabb DP, Russell RA, Malik R, et al. Frequency of visual field testing when monitoring patients newly diagnosed with glaucoma: mixed methods and modelling. Southamptom: Health Services and Delivery Research; 2014.

21. Brown MM, Brown GC, Sharma S, et al. Utility values associated with blindness in an adult population. $\mathrm{Br} \mathrm{J}$ Ophthalmol. 2001;85(3):327-31.

22. Christ SL, Lee DJ, Lam BL, et al. Assessment of the effect of visual impairment on mortality through multiple health pathways: structural equation modeling. Invest Ophthalmol Vis Sci. 2008;49(8):3318-23.

23. Australian Government Department of Health. Technical guidelines for preparing assessment reports for the Medical Services Advisory Committee-Medical Service Type: Therapeutic. 2016.

24. Craven ER, Katz LJ, Wells JM, et al. Cataract surgery with trabecular micro-bypass stent implantation in patients with mild-tomoderate open-angle glaucoma and cataract: two-year follow-up. J Cataract Refract Surg. 2012;38(8):1339-45.

25. Fea AM. Phacoemulsification versus phacoemulsification with micro-bypass stent implantation in primary open-angle glaucoma: randomized double-masked clinical trial. J Cataract Refract Surg. 2010;36(3):407-12.

26. Fea AM, Consolandi G, Zola M, et al. Micro-bypass implantation for primary open-angle glaucoma combined with phacoemulsification: 4-year follow-up. J Ophthalmol. 2015;2015:795357.

27. Fernandez-Barrientos Y, Garcia-Feijoo J, Martinez-de-la-Casa $\mathrm{JM}$, et al. Fluorophotometric study of the effect of the glaukos trabecular microbypass stent on aqueous humor dynamics. Invest Ophthalmol Vis Sci. 2010;51(7):3327-32.

28. Vold SD, Voskanyan L, Tetz M, et al. Newly diagnosed primary open-angle glaucoma randomized to 2 trabecular bypass stents or prostaglandin: outcomes through 36 months. Ophthalmol Ther. 2016;5(2):161-72.
29. Katz LJ, Erb C, Carceller GA, et al. Prospective, randomized study of one, two, or three trabecular bypass stents in open-angle glaucoma subjects on topical hypotensive medication. Clin Ophthalmol. 2015;9:2313-20.

30. NHMRC. For the screening, prognosis, diagnosis, management and prevention of glaucoma 2010. Canberra: Australian Government Publisher; 2010.

31. Ternouth AM, Chapman M, Modha R. An assessment of the variation in accepted ICERs by disease type: results from four HTAs. Value Health. 2010;13(7):PHP66, A416.

32. Harris AH, Hill SR, Chin G, et al. The role of value for money in public insurance coverage decisions for drugs in Australia: a retrospective analysis 1994-2004. Med Decis Making. 2008;28(5):713-22.

33. Ahmed IK, Podbielski DW, Patel V, Falvey H, Murray J, Botteman M, Goeree R. A Canadian cost-utility analysis of 2 trabecular microbypass stents at time of cataract surgery in patients with mild to moderate open-angle glaucoma. Ophthalmol Glaucoma. 2020;3(2):103-13.

34. Fea AM, Cattel F, Gandolfi S, Buseghin G, Furneri G, Costagliola C. Cost-utility analysis of trabecular micro-bypass stents (TBS) in patients with mild-to-moderate open-angle Glaucoma in Italy. BMC Health Serv Res. 2021;21(1):824.

35. Nieland K, Labbe A, Schweitzer C, Gicquel G, Kleintjens J, Ostawal A, Treur M, Falvey H. A cost-effectiveness analysis of iStent inject combined with phacoemulsification cataract surgery in patients with mild-to-moderate open-angle glaucoma in France. PLoS ONE. 2021;16(6): e0252130. https://doi.org/10.1371/journ al.pone.0252130.

36. Patel V, Ahmed I, Podbielski D, Falvey H, Murray J, Goeree R. Cost-effectiveness analysis of standalone trabecular micro-bypass stents in patients with mild-to-moderate open-angle glaucoma in Canada. J Med Econ. 2019;22(4):390-401. 